\title{
Second Language Interactional Competence in Classroom Discursive Practices
}

\author{
Dian Misesani \\ Pendidikan Bahasa dan Sastra \\ Universitas Negeri Surabaya \\ Surabaya, Indonesia \\ dianmisesani@mhs.unesa.ac.id
}

\author{
Lies Amin Lestari \\ Pendidikan Bahasa dan Sastra \\ Universitas Negeri Surabaya \\ Surabaya, Indonesia
}

\begin{abstract}
The purpose of this study is to identify the forms of discursive practices that make evident to the demonstration of second language interactional competence, and describing the manners of second language interactional competence shiwed by participants' employment of linguistic and interactional resources in the occuring discursive practices. This qualitative research with a case study design was carried out through thirteen classroom observations. The classroom discursive practices were observed and transformed into written form to be displayed and analyzed for findings. The findings showed that there were four forms of discursive practices comprised students' dialogue, lecturer-students dialogue, students' monologue, and lectures or instructions. Among the four, the students' dialogues was the most form of discursive practices that have potential to the demonstrations of second language interactional competence. The students were able to achieve intersubjectivities in collaborative dialogues by employing their linguistic and interactional competence. It can be concluded that the students took benefit from collaborative dialogue practices to drill fluency and accuracy that gave impact to the improvement of their second language interactional competence.
\end{abstract}

Keywords - second language interactional competence, intersubjectivity, classroom discursive practices, collaborative dialogue

\section{INTRODUCTION}

The " 21 st century skills" that deal with critical thinking, problem solving, communication, and collaboration, has became a challenge movement for learners and educators for more than a decade now [1]. The mastery of these skills would certify that students of college courses are well prepared to have careers in the global society, including the students of English college.

Second language interactional competence, or L2-IC, is valuable to be acquired and mastered for the students' interactive communication that is useful for their forthcoming workforce. L2-IC involves the mastery of language subsystem or 'resources' such as: 1) identity resources, 2) linguistic resources or LR, and 3) interactional resources or IR [2]. However, English oral proficiency is a demanding task. Many of college students are frustated by their poor English oral proficiency, even though they have spent their extra time on English learning. In facing such problems, language teachers and lecturers have been actively experimenting with many methods for improving students' competence in English. Given this phenomenon, this research aims at finding: 1) the forms of classroom discursive practices that make evident to the demonstration of L2-IC, and 2) how the students demonstrate L2-IC in the occuring classroom discursive practices.

The purpose of this study is to identify the forms of discursive practices that have the potential to second language interactional competence and to justify that not all forms of discusive practices can create intersubjectivity.

\section{THEORETICAL FRAMEWORK}

\section{A. Interactional Competence}

Sociolinguistic SLA founded by Charles Ferguson (1997) was the theory that grounded Young's interactional competence theory for the first time [3]. In formulating the theory, he employed the term 'interactive practices' [4] which further termed as 'discursive practices' [5]. Further, Young elaborated the notion of discursive practices [6] and of interactional competence [2] [7] in language learning and teaching. He stated that interactional competence may occur in discursive practices shown by the employement of identity resources, linguistic resources and interactional resources to achieve intersubjectivity. Here, language teaching and learning was regarded as one of discursive practices referring to the processes of how learners practicing second language in particular context and that the second language could be a context in its own.

\section{B. Swain's Output Hypothesis and Collaborative Dialogue within Sociocultural Framework.}

Vigotsky's sociocultural theory of mind inspired Lantolf and his colleagues (2006) to address the importance of sociocultural dimensions of SLA. According to Lantolf and Thorne [8] the sociocultural approaches took into account on the importance of applying research to practice by understanding communicative and cognitive processes as inseparable from humanistic issues of self agency and the effects of participation in cultural activity. Swain [9] was with Lantolf in reformulating her previous output hypothesis [10] and thus, reframing it into sociocultural framework. She argued that both output and collaborative dialogue are the 
two faces present in an utterance [9], and that collaborative dialogue is a dialogue in which two or more speakers are engaged in the joint construction of language - ot knowledge of language - to attain problem solving and knowledge building [11] [12].

In this way, the notion of interactional competence [2] [7] and discursive practices [6] are synchronized with the concept of collaborative dialogue [9] [11] regardless of what entity is being mutually constructed or shared. Therefore, this theoretical framework is the guidance to examine the manner of employing linguistic and interactional resources to exhibit intersubjectivity in collaborative dialogues.

\section{METHOD}

This is a qualitative research with a case study design. The observations took place in the speaking class of a tertiary school of foreign language. Twelve students of second semester and a lecturer became the participants.

This research applied data triagulation which involved the use of different data sources taken from observation sheets and recordings. As well, this research applies theoretical triangulation since it combines a theory and a hypothesis as can be seen in theoretical framework presented above.

\section{RESULTS AND DISCUSSION}

The results of this research were taken from thirteen meetings observation of speaking lecture once a week. The allocation of time in every meeting was distributed into four forms of discursive practices. Those are L-SS dialogue, SSSS dialogue, lecture/instruction, and SS monologue. The extent of those forms were illuminated by calculating the allocation of time for classroom discursive practices and summarized into a table (Table 1). The forms that made evident to second language interactional competence are discussed in part A, whereas the demonstrations of second language interactional competence in collaborative dialogue are presented in part $\mathrm{B}$.

TABLE I. THE FORMS OF CLASSROOM DISCURSIVE PRACTICES AND THE ALLOCATION OF TIME ( ${ }^{*}=$ MINUTES) .

\begin{tabular}{|c|c|c|c|c|c|}
\hline Meeting & $\begin{array}{c}\text { L-SS } \\
\text { dialogue }\end{array}$ & $\begin{array}{c}\text { SS-SS } \\
\text { dialogue }\end{array}$ & $\begin{array}{c}\text { Instruc } \\
\text { tion }\end{array}$ & $\begin{array}{c}\text { SS } \\
\text { mono } \\
\text { Logue }\end{array}$ & $\begin{array}{c}\text { Total } \\
\left({ }^{6}\right)\end{array}$ \\
\hline I & $50^{\prime}$ & - & $10^{\prime}$ & $40^{\prime}$ & $100^{\prime}$ \\
\hline II & $60^{\prime}$ & - & $40^{\prime}$ & - & $100^{\prime}$ \\
\hline III & $15^{\prime}$ & $40^{\prime}$ & $10^{\prime}$ & $40^{\prime}$ & $105^{\prime}$ \\
\hline IV & $30^{\prime}$ & $60^{\prime}$ & $10^{\prime}$ & - & $100^{\prime}$ \\
\hline $\mathbf{V}$ & $10^{\prime}$ & $80^{\prime}$ & $10^{\prime}$ & - & $100^{\prime}$ \\
\hline VI & $20^{\prime}$ & $70^{\prime}$ & $10^{\prime}$ & - & $100^{\prime}$ \\
\hline VII & $60^{\prime}$ & - & - & - & $60 ’$ \\
\hline VIII & $35^{\prime}$ & $60^{\prime}$ & 5 , & - & $100^{\prime}$ \\
\hline IX & $10^{\prime}$ & $70^{\prime}$ & 5, & - & $85^{\prime}$ \\
\hline $\mathbf{X}$ & $10^{\prime}$ & $50^{\prime}$ & 5 , & $35^{\prime}$ & $100^{\prime}$ \\
\hline XI & $30^{\prime}$ & $50^{\prime}$ & $10^{\prime}$ & - & $90^{\prime}$ \\
\hline XII & $15^{\prime}$ & $75^{\prime}$ & $10^{\prime}$ & - & $100^{\prime}$ \\
\hline \multirow[t]{2}{*}{ XIII } & $10^{\prime}$ & $50^{\prime}$ & - & - & $60^{\prime}$ \\
\hline & 355 & 605 & 125 & $115^{\prime}$ & $1200^{\prime}$ \\
\hline
\end{tabular}

\section{A. The form of discursive practices that make evident to the demonstration of L2-IC.}

From the first to thirteenth meeting had been observed, most of the classroom discursive practices were performed in the form of dialogues comprised students-students (SS-SS) dialogues and lecturer-students (L-SS) dialogues. The first most performed classroom discursive practices were SS-SS dialogues, the second most performed classroom discursive practices were L-SS dialogues, while the other two were in the forms of students' monologues and the lecturer's lecture or instruction.

The table above shows that almost every meeting of speaking lecture lasted in one hundred minutes. Students' monologue was the kind of discursive practice that happened only three times and lasted for about thirty five to fourty minutes. This kind of discursive practice revealed each student's speaking ability individually since a monologue is a self speech performed by one participant while the other participants were only listening to the speech being performed. In this way, there were little possibility to obeserve L2-IC in monologues given that no occurrence of interactional resources such as turn taking or speech acts, except a speech done by a single participant within a certain length of time. Likewise, there were minor apparent of L2-IC during the lecturer's instruction or lecture since the students only listening to the instruction or lecture and giving insignificant respond by saying 'yes' or nodding. Such responds were just some trivial revealing of intersubjectivities in that the students understood to not taking turn while the lecturer was giving instruction or lecturing.

The L-SS dialogues were always present in every meeting. The constancy of L-SS discursive practices in each meeting revealed how the lecture always involved the students in any kind of dilaogues related to daily communication. In the first meeting, as an evident, the lecturer initiated the discursive practice and instructed the students to practice their spoken English as much as possible and try to minimize the use of bahasa Indonesia during the speaking lecture. In this manner, such environment of L2 spoken language was created by the lecturer by which the motivation to employ L2 linguistic resources was also built.

The SS-SS dialogues were present in nine meetings of all which concerned with the creation of students' authentic exchanges of daily communication. The students were assigned in pairs of two or three to make collaborative dialogues by employing their linguistic and interactional resources. They were allowed to choose their partners or groups freely started from the third to sixth meeting. Afterwards, the members of pairs or groups were made by the lecturer's determination. There were lots of L2-IC demonstration that evidently present in SS-SS collaborative dialogues characterized by the exhibit of intersubjectivities. Those intersubjectivities exhibited by the students were related to meaning making, enriching the range of vocabularies, knowing how to manage interaction, building knowledge of language, etc. In this way, collaborative dialogues had become a purposeful dialogic approach in 
which the lecturer plan and direct the classroom discursive practices related to pairs' or groups' members with particular learning goals in view.

This findings entailed that it was necessary to reveal the kinds of classroom discursive practices in investigating the demonstration of L2-IC, since they were observable in the extent of discursive practices. In other words, there were observable connections between classroom discursive practice and L2-IC, since there were possibilities to find the traits of L2-IC in classroom discursive practices. However, this findings proved that not all of the classroom discursive practice could make evident to the demonstration of L2-IC characterized by the exhibit of intersubjectivity. The unforeseen findings were revealed that monologues and the lecture or instruction were the kinds of discursive practices that made no evident of L2-IC whenever performed either by students or lecturer. The expected findings of RQ1 were showed in the form of dialogic discursive practices comprises L-SS and SS-SS dialogues, but then again, the LSS dialogues made smaller number of evident than the SSSS dialogues in exhibiting the intersubjectivities. The SS-SS collaborative dialogues were the most dialogic discursive practices which have potential to the majority of L2-IC demonstrations characterized by the exhibit of intersubjectivies.

\section{B. The demonstration of L2-IC in the occuring SS-SS collaborative dialogues.}

The demonstration of L2-IC started to appear from the eighth to the thirteenth meeting. Here, the data displayed are taken from the SS-SS collaborative dialogues in ninth and eleventh meetings. The SS-SS collaborative dialogues in the ninth meeting were performed on the basis of particular topics given by the lecturer, whereas those performed in the eleventh meeting were based on free topics. They were performed by four groups consisted of three fixed members both in the ninth and eleventh meetings.

In the ninth meeting, L2-IC was demonstrated by group 1 consisted of S1, S2, S6. After choosing three topics written on three different pieces of paper, they started to perform in front of the class. The choosen topics were rain, mother, and cat. The extracted data are displayed as below:

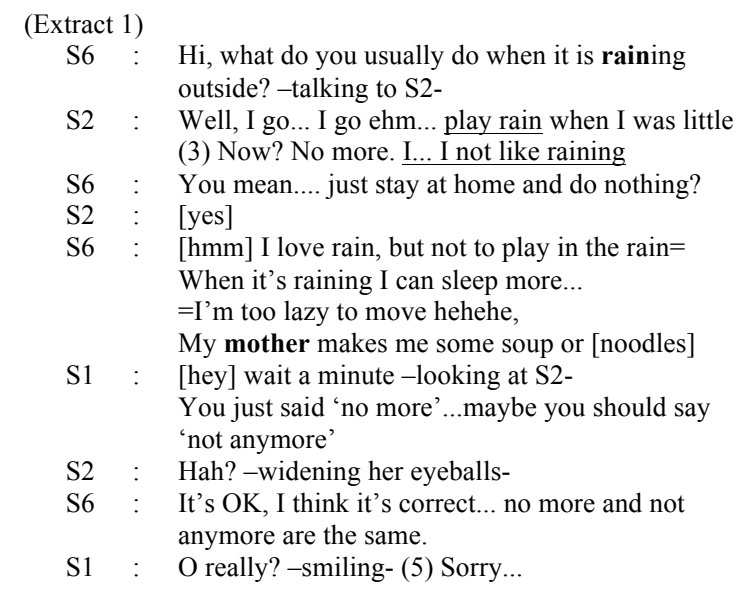

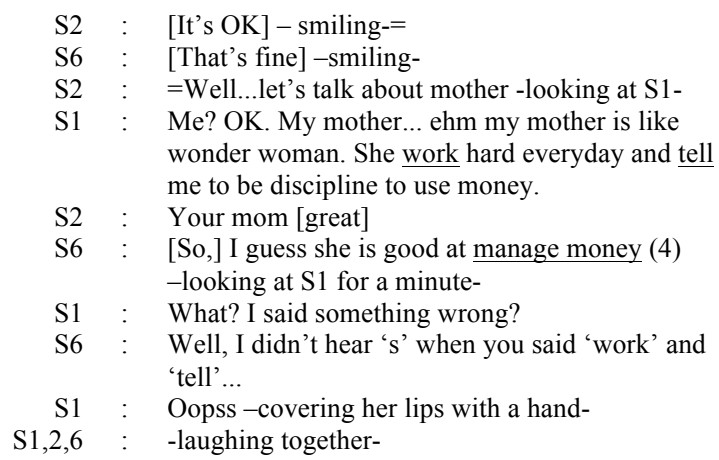

The extract above shows how the students performed discursive practice by employing their linguistic resources based on the chosen topic. Each members of group 1 had different linguistic resources to be employed in their discursive practices. S1 had enough language to get by with sufficient vocabulary and could keep going fluently in her discursive practice. S1 had sufficient range of vocabulary as she thought that 'no more' was not correct instead of 'not anymore'. But S6 who had the more linguistic resources than S2 had confirmed that both 'no more' and 'not anymore' were appropriate to be employed. Although spoke fluently, S1 still made basic mistakes in employing accurate pattern of subject-verb agreement when saying 'she make... and tell...' which should be 'she makes... and tells...'.

S2 used basic sentence patterns with memorised phrase in some short utterances with pauses (I go... I go.. play rain). She showed limited control of few simple sentence patterns in saying 'play rain' which should be 'playing in the rain' and 'I not like raining' which should be 'I don't like rain'. Although S2 had limited linguistic resources as shown by her employment in discursive practices, she could make herself understood by the other members in the group.

S6 had the most capacity in linguistic resources shown by such proper employment of linguistic resources. Nearly all of her discursive practices had shown proper employment of linguistic resources. She could express herself fluently and spontaneously, as well as maintain a high degree of grammatical accuracy, except for one phrase -'at manage money'- was not proper. The appropriate word used after preposition 'at' is a noun, and since 'manage' is a verb, it should be attached by '-ing' behind that could form 'managing' as a noun. Overall, S6 had a good command of broad range of linguistic resources to express herself clearly in appropriate topics.

Despite the different exhibit of linguistic resources among the members of group 1, they were all able to manage the interaction in a discursive practice related to context such as turn taking and repair. They can easily turn from one topic (rain) to another (mother) uneffortlessly. Overall, they could initiate, maintain and close simple face-to-face conversations on familiar topics (rain-mother). In addition, they could repeat back part of what S2 had said (no more) to confirm mutual understanding which thus, exhibit intersubjectivity in their collaborative dialogue. In conclusion, the result above showed that the demonstration of L2-IC occured in students' collaborative dialogue which members of the group engaged 
by their output on the basis on particular topics and at the same time they construct knowledge about language.

In the eleventh meeting, the same students were assigned to make a group by which joining S1, S2, and S6 again. This time the topics of discursive practices were not determined by the lecturer. Each group were allowed to chose the topics they interested in, as long as they could keep going their discursive practice in particular given time. Below is the extract of group 1 discursive practices in the eleventh meeting:

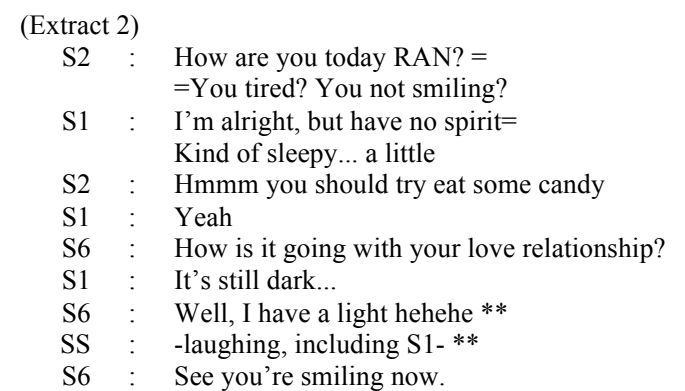

The way S2 asked question was not proper in that she did not use interrogative. Afterward, S2 produced such improper utterance again by saying: "You not smiling", which should be said: "You are not smiling". She lost the linking verb 'are' in questioning the proper form: "Are you tired?" and stating: "you are not smiling". In the next turn, S2 produced a proper statement in suggesting S1 to eat some candy. In this way, S2's linguistic resource was still limited in that she could employ simple structure correctly, but still systematically made basic mistakes in accuracy. However, S2 uttered the statements fluently with little pause and had enough vocabularies to express herself which made her sufficient in fluency and range of vocabulary. Similarly, her employment of interactional resource was good since she initiate the talk in this group discursive practice.

When S6 asked S1 about her love relationship, she thought that S1 had a problem with her boyfriend. But actually, S1 had not has any boyfriend yet as she said "it's still dark". And so S1, who did not seem so enthusiastic at the first time, was finally smiling when S6 said she got a light for S1's love relationship. Even more, all students in the classroom laughed.

S6 could express herself spontaneously, and consistently maintain a grammatical accuracy which means she had high level of linguistic resources and interactional resources. Knowing that a member of her group, S1, was not in the mood, S6 tried to comfort her by making a joke. The joke S6 made had caused the students in the classroom laugh, and they constructed inter-subjectivity or mutually understanding that that was a joke. Saying, "I get a light" did not mean literally that S6 would give S1 a torch or anything that produced a light for a love relationship. Saying that did not also mean that S6 did not understand what S1 meant by saying: "It's still dark..." S6 just made a joke to entertain S1 and all the audience.
The results displayed in extract 1 and extract 2 showed that the students' collaborative dialogue was the form of discursive practice that could create acquisition and learning in spoken language which therefore could guide them to master L2-IC. In addition, the students linguistic resources were employed in their output and their interactional resources were employed in such collaborative dialogues that create or exhibit intersubjectivities as the characteristic of L2-IC. Here, the close relationship between L2-IC and collaborative dialogue lies in the joint creation of mutual understanding or intersubjectivity [11] [13] and in the concept that output or performance exceeds competence [7] [11].

Students' monologue was the kind of discursive practice that happened only three times and lasted for about thirty five to fourty minutes. This kind of discursive practice revealed each student's speaking ability individually since a monologue is a self speech performed by one participant while the other participants were only listening to the speech being performed. There were little possibility to obeserve L2-IC in monologues given that no occurrence of interactional resources such as turn taking or speech acts, except a speech done by a single participant within a certain length of time. In other words, it was such trivial evidence that monologues can exhibit silent inter-subjectivity. The practice of monologue by a student whose classmates were in the room and paying attention to her/him could hardly identify that there were inter-subjectivity and interactional competence. In this case, this study is not in line with Young's [7] statement which said "it is possible to identify inter-subjectivity and interactional competence when a single person speaks in the discursive practice", since this study did not result that way.

A number of empirical studies had also conducted research in relation to interactional competence and discursive practices. A study about the construct and the manner of interactional competence was conducted by Donald [14]. He examined the episodes of interaction among three language instructors and their learners. The data were taken from about twenty four hours of classroom interactions in three EFL classroom in a university. The finding showed that intersubjectivity was achieved by means of affordance offering from the lecturer during the interaction episodes. However, the participants of Donalds (2015) study, who happened to be teachers, had such mistaken belief that interactional competence was a strategy or method to enhance the interaction between the teacher and the students. Thus, the second language classroom study was set mostly for teacher-student interactions in the form of questionanswer. On the contrary, findings of the current research showed that dialogic approach was used by the lecturer in which the students habitually practiced their English in dialogues, both with the lecturer and their classmates. The lecturer in the current study allocated such large amount of time for dialogic discursive practices, but the allocation of time for SS-SS collaborative dialogues were larger than that for L-SS dialogue. The distinction above, actually, depended on how the lecturer or teacher set the classroom discursive practices in language teaching and learning. Finally, Donald 
[14] argued that the construct of interactional competence is need to be redefined. In this way, there is a gap between this previous study and the current research in that the previous findings showed that inter-subjectivity was achieved by the guidance from the teacher whereas in this research, the intersubjectivity was achieved in the students' collaborative dialogue.

In relation the previous study conducted by Kley [15], the current research is a confirmatory. The previous and current researches are in line in finding that the participants who provide repair are usually at a higher level to other participants. The similarity to the current research was in the paired speaking to maintain inter-subjectivity, as the current also found that inter-subjectivity exhibited in the students' collaborative dialogues. There was a difference between the previous and the current research. The previous study investigated the students speaking ability by the paired speaking tests only, while the current presents the everyday lesson of classroom discursive practices, including speaking tests, to display the demonstration of L2 interactional competence. In addition, in measuring the students' speaking ability, Kley (2015) used CEFR which was also used in the current research. Kley's (2015) research findings entailed that interactional competence were strongly demonstrated in the form of SS-SS dialogue characterized by the exhibit of intersubjectivity. In this way, the current research is a confirmatory to Key's (2015) research.

A review article about the features of classroom discourse was conducted by Derakhshan et.al. [16]. They investigated the four features of classroom discourse such as the importance of classroom discourse, the amount of time for teacher talk and the effects of giving feedback, the impacts of teacher's question, and error treatment. The finding showed that communication in the classroom was mainly teacher-initiated and the teacher should be experienced to manage the classroom in acommunicative way which will lead to more learning. They suggested that the students should be given more opportunities to participate in classroom discourse and enhance their language ability in learning English by using English. In addition, the topics should be familiar to students so that they could participate in the discursive practice more willingly and found learning more interesting. The findings between the current and this previous study is contradictory since the current research found that the classroom discursive practices were mainly SS-SS collaborative dialogue. However, the current study is very much of Derakhshan's et.al. (2015) opinion that teaching and language learning, specifically speaking subject, should involve students' active participation in the classroom discursive practice. In addition, the current research also found that the topics of SS-SS dialogues were prepared by the lecturer on the basis of familiarity to students such as; rain, mother, cat, etc.

Marshall [17] conducted a classroom action research in which he investigated the way to develop interactional competence by proposing a set of teaching practices involving elements of project work, such as interactive and collaborative activity. In this proposal, he emphasized that the goal of the project should be negotiated in small groups.
He prepared a lesson plan with the intention to engage learners in peer interactions through a variety of activity and dialogues. The findings of this research showed that by implementing Marshall's lesson plan, the students were collaboratively working toward a list of questions. They were also engaged in mutual intention as they solve the problem. In this way the construction of inter-subjectivity as a reflection of interactional competence could be seen. Marshall (2012) found a conclusion that his approach was aimed at the acquisition of interactional competence rather than language itself. However, the main focus of his study was to engage students in collaborative problem-solving activities through the employment of their linguistic resources. The similarity between the current research and Marshall's (2012) is in the investigation of second language (English) interactional competence in the classroom. The difference is in the methodology of which the current research is such an observational study that the data were collected from the observations without the researcher's interference in lesson plan. In the contrary, Marshall's research (2012) was purposefully proposed such lesson plan to be implemented in the classroom. The interesting finding of his research was that, there was no evidence of teacher talk in the trancript excerpt. Actually, in the complete transcript, the teacher only came temporarily over the group to ask if there were any problems. He claimed that if the teacher was assigned to minimal role, the students took control prominence in interaction referred to the exercise of interactional competence. This means Marshall's (2012) research is confirmatory to the current research as it suggested interaction and collaborative activity for second language classroom.

\section{CONCLUSION}

In conclusion, the most form that had the potential to the demonstration of L2-IC was SS-SS dialogue as there were plenty of time given for SS-SS dialogue in which students collaboratively performed their dialogues. That is to say that students collaborative dialogue resulted not only mutual understanding and knowledge building, but also good relationship among the students to exceed their language learning and proficiency. And in relation to language learning, the collaborative dialogue also exhibited intersubjectivity when parcticipants construct language knowledge by practicing the knowledge at the same time. Thus, this kind of dialogic approach would be effective for students to acquire L2-IC which has such similar characteristics with 21 st century skills as to prepare the students of higher education into the workforce and real social life. However, monologue and lecture discursive practices were the other two forms found in this research, which did not exhibit inter-subjectivity. They were considered as one way communication, in which the other participants only employed participation framework as an official listeners. Other than that, these official listeners did not employ LR and IR as other resources of L2-IC to be brought in interaction. Such a way did not exhibit intersubjectivity because it hardly recognized whether the participants understood or not if they remained in silence. 
The mutual understanding or intersubjectivity could be identified through verbal interactions and/or nonverbal cues, but silence, as such respond from other participants that neeeded the employment of LR and IR. In addition, this research believes that there is no L2-IC if there is only one resource employed in a discursive practice. This result has become a disagreement over Young's viewpoint which says that it is possible to identify intersubjectivity in a single speaker discursive practice. Thus, the researcher emphasizes that the concept of L2-IC has been made identical with collaborative dialogue in second language teaching and learning. Collaborative dialogue in second language education is when the target language used by learners and teachers/lecturers in relation to particular context/s, by which makes learning the target language of itself. In this way, language used like practicing L2-IC does not only facilitate language learning, but also educates the students to be proficient in second language actual interactions.

\section{REFERENCES}

[1] AACTE, "21st Century Knowledge and Skills in Educator Preparation," Pearson, New York, 2010.

[2] R. Young, "Interactional Competence in Second Language Learning, Teaching, and Testing," in A Handbook of Research in Language Learning and Teaching, New York, Routledge, 2011, pp. 427-443.

[3] R. Young, "Sociolinguistic Approach to SLA," Annual Review of Applied Linguistic, vol. 19, pp. 105-132, 1999.

[4] Hall, Joan K., "A Prosaics Interactions: The development of interactional competence in another language," in Culture in Second Language Teaching and Learning, E. Hinkel, Ed., Cambridge, Cambridge Univeristy Press, 1999, pp. 137-151.

[5] R. Young, "Language teaching and learning as discursive practices," in Language Learning and teaching as Social Interaction, New York, Palgrave Macmillan, 2007, pp. 251-271.

[6] R. Young, "Discursive Practices in Language Learning and Teaching," The annual meeting of teh America Association of Applied Linguitics, p. 36, 6-9 March 2010.

[7] R. Young, Language and Interaction: An advanced rescource book, London: Routledge, 2008.

[8] J. P. Lantolf et.al., "Sociolcultural Theory and Second Language Learning," Van Patten LEA, no. 5/19/2006, pp. 197-221, 2006.

[9] M. Swain, "The Output Hypothesis and Beyond: Mediating acquisition through collaborative dialogue," in Sociocultural Theory and Second Language Learning, Oxford, Oxford University Press, 2000, pp. 97-115.

[10] M. Swain, "Three functions of output in second language learning," in Principles and Practice in Applied Linguistics, Oxford, Oxford Course University, 1995, pp. 125-144.

[11] M. Swain, "Collaborative Dialogue: Its contribution to second language learning," Revista Canaria se Estudios Ingleses, vol. 34, pp. 115-132, 1997.

[12] M. Swain, "The Output Hypothesis: Theory and research," in Handbook of research in Second Language Teaching and Learning, New Jersey, Lawrence Erlbaum Associates, 2005, pp. 471-483.

[13] R. Young, "Assessing Interactional Competence," in Language in Interaction: An Advanced Resource Book, London, Routledge, 2008a, pp. 282-288.

[14] S. Donald, A Study of Interactional Competence in the Taiwanese English as a Foreign Language Classroom Context, Newcastle, UK: Newcastle University, 2015.

[15] K. Kley, Interactional Competence in Paired Speaking Tests: Role of Paired task and test-taker speaking ability in co-constructed discourse, Iowa: University of Iowa, 2015.

[16] A. Derakhshan et.al., "Features of Classroom Discourse," International Journal Basic Science and Applied Research, vol. 4, pp. 240-244, 2015.

[17] N. Marshall, "Helping Learners Develop Interactional Competence through Project Work in the Language Classroom," Language Education in Asia, vol. 3, no. 2, pp. 168-175, 2012.

[18] M. Swain, "The Output Hypothesis: Just Speaking and Writing Aren't Enough," The Canadian Modern Language Review, vol. 50, no. October, pp. 158-164, 1993. 